\title{
A comparative study of defibrillation and cardiopulmonary resuscitation performance during simulated cardiac arrest in nursing student teams
}

Sissel I Eikeland Husebø $\varnothing^{1 *}$, Conrad A Bjørshol ${ }^{2}$, Hans Rystedt ${ }^{3}$, Febe Friberg ${ }^{1,4}$ and Eldar Søreide ${ }^{2}$

\begin{abstract}
Background: Although nurses must be able to respond quickly and effectively to cardiac arrest, numerous studies have demonstrated poor performance. Simulation is a promising learning tool for resuscitation team training but there are few studies that examine simulation for training defibrillation and cardiopulmonary resuscitation (D-CPR) in teams from the nursing education perspective. The aim of this study was to investigate the extent to which nursing student teams follow the D-CPR-algorithm in a simulated cardiac arrest, and if observing a simulated cardiac arrest scenario and participating in the post simulation debriefing would improve team performance.

Methods: We studied video-recorded simulations of D-CPR performance in 28 nursing student teams. Besides describing the overall performance of D-CPR, we compared D-CPR performance in two groups. Group A $(n=14)$ performed D-CPR in a simulated cardiac arrest scenario, while Group $B(n=14)$ performed D-CPR after first observing performance of Group A and participating in the debriefing. We developed a D-CPR checklist to assess team performance.

Results: Overall there were large variations in how accurately the nursing student teams performed the specific parts of the D-CPR algorithm. While few teams performed opening the airways and examination of breathing correctly, all teams used a 30:2 compression: ventilation ratio.

We found no difference between Group A and Group B in D-CPR performance, either in regard to total points on the check list or to time variables.

Conclusion: We found that none of the nursing student teams achieved top scores on the D-CPR-checklist. Observing the training of other teams did not increase subsequent performance. We think all this indicates that more time must be assigned for repetitive practice and reflection. Moreover, the most important aspects of D-CPR, such as early defibrillation and hands-off time in relation to shock, must be highlighted in team-training of nursing students.
\end{abstract}

Keywords: Defibrillation, Cardiopulmonary resuscitation, Patient simulation, Nursing students

\section{Introduction}

Nurses and nursing students must be able to respond correctly in the event of a cardiac arrest both inside and outside hospitals [1-4]. Most nursing education institutions have resuscitation training within their curricula to

\footnotetext{
* Correspondence: sissel.i.husebo@uis.no

'Department of Health Studies, Faculty of Social Sciences, University of

Stavanger, Stavanger 4036, Norway Full list of author information is available at the end of the article
}

meet these expectations and to ensure that students are competent at commencing life support in cases of cardiac arrest. In spite of this, previous studies in the nursing research literature have described poor retention of knowledge and skills in performing resuscitation [3,5-7]. Several educational methods of improving cardiopulmonary resuscitation (CPR) have been tried out but both content and methods lack standardization [3]. Nevertheless, simulation can be used to meet these
C Biomed Central 
demands by creating learning opportunities that are unavailable in clinical practice, such as defibrillation and CPR (D-CPR) $[8,9]$.

Several studies have been performed using cardiac arrest simulation to improve resuscitation performance by nurses $[7,10-13]$. However, there are few studies from the nursing education perspective that examine simulation for learning CPR. A previous study demonstrated that the nursing students needed several simulations to perform CPR accurately [14]. Scherer et al. [15] examined pre-and post-test knowledge of cardiac arrest and found no difference between the experimental group (simulation) and control group (case study seminar). Two other studies measuring satisfaction and/or self-confidence of nursing students after a cardiac arrest simulation demonstrated that students rated the experience as positive, enjoyable and instructive [16] and perceived the design and implementation to be very satisfying [17]. A study in medical practice demonstrated that observing simulation and participating in the post simulation debriefing in combination with participating in simulation improved performance in resuscitation [18]. A study of the briefing part of simulation in nursing education concluded that presupposing a higher level of resuscitation skills than expected in nursing education might interfere with opportunities to learn from simulation experiences [19]. Husebø et al. [20] identified three phases in resuscitation teamwork corresponding to the three first steps in the BLS algorithm: stating unconsciousness, preparing for resuscitation and initiating resuscitation, but questions remain unanswered as to which extent the nursing student teams followed the D-CPR algorithm and if different conditions in simulation improved team performance.

In this study, our aim was to investigate the extent to which nursing student teams followed the D-CPR algorithm. Moreover, we wanted to examine if observing one simulated cardiac arrest scenario and participation in one debriefing could improve team performance of D-CPR in a subsequent simulation.

\section{Methods}

\section{Study participants}

We invited half the cohort $(n=81)$ of nursing students from a three-year nursing education program at the University of Stavanger, Norway, to participate in the study. The students were in their last semester. Five faculty members participated as facilitators. The study was approved by the Norwegian Social Science Data Services (NSD) and the University of Stavanger but the ethics committee of the Western part of Norway declined to consider the application because the study did not involve patients or relatives. All students received oral and written information about the study at the start of the semester, and all participants signed an informed consent before being included in the study, confidentiality having been guaranteed. All 81 nursing students asked (72 female and 9 male) agreed to participate in the study; the average age was 26 (range $22-49$ years). Each of the 28 nursing student teams consisted of between two and four team members. Eight of the teams included both males and females, while the rest consisted of females only.

\section{Setting}

The study took place in a simulation centre where the simulation environment resembled a room in an out-ofhospital rehabilitation unit. A full-size patient simulator (SimMan, Laerdal Medical Inc., Norway) was controlled by an operator in an adjacent room. The patient simulator was placed in a bed and exhibited clinical signs such as palpable pulses, breath movements and sounds. A speaker located in the mannequin's head transmitted the voice of the operator, thus giving the impression that the 'patient' could talk. The room was equipped with a training semi-automatic defibrillator (Heartstart FR2, Laerdal Medical Inc., Norway), oxygen, backboard, medications, an oro-pharyngeal airway and a bag-mask manual ventilator. The simulations were video-recorded by two separate video cameras.

\section{Design and research procedures}

The results are based on video-recordings of 28 simulated cardiac arrest scenarios in nursing education. The data were collected in February and March 2008. We first conducted a descriptive study of the overall D-CPR performance in 28 nursing student teams. Further, we compared performance of D-CPR in two groups of nursing student teams. Group A (14 teams) performed DCPR in a simulated cardiac arrest scenario, while Group B (14 teams) performed D-CPR after first observing performance of Group A and participating in the debriefing.

Three weeks prior to the simulation, all students received the team schedule list, a short description of the scenario and the learning objectives. The learning objectives were: 1) using the D-CPR guidelines in practice, and 2) optimizing teamwork in resuscitation teams. The D-CPR course was developed for the last semester in nursing education and comprised a two-hour lecture in class about the semi-automatic defibrillator. All teams were given $45 \mathrm{~min}$ of individual practical training in CPR and use of a semi-automatic defibrillator [21,22] before participating in the team-based simulation of a cardiac arrest. For each simulation, teams in Group A participated in the simulation scenario while teams in Group B were present in the room to observe. After completion of the post-simulation debriefing, Group B performed the simulation scenario, while Group A observed (Figure 1). 


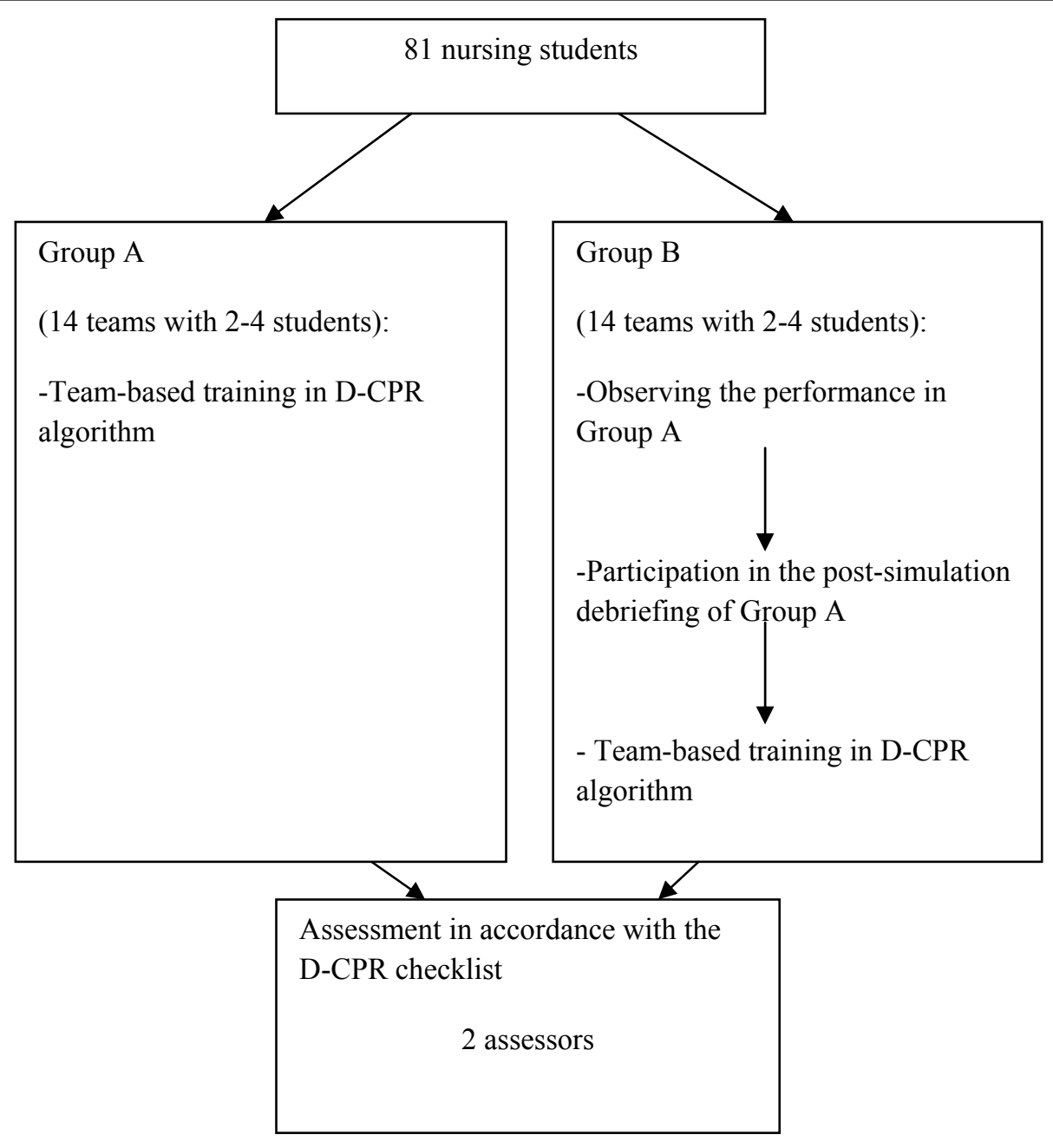

Figure 1 Outline of research design.

Prior to the simulation session, the facilitator gave all teams a 15-minute briefing regarding the function of the mannequin and the use of the medical equipment, and repeated the learning objectives. The following statement introduced the simulated scenario: The patient is a 71 year-old woman who has suffered an upper femur fracture and has been moved to an out-of-hospital rehabilitation unit without a physician present. The patient has a history of angina pectoris and is now complaining about chest pain. Your team are now required to manage this patient. The simulation started with the nurse entering the room to see if the patient had finished breakfast. After a few minutes with chest pain, the patient went into a cardiac arrest with a shock able rhythm. We discontinued the simulation 1 min after the first shock. Following the simulation, the students participated in the debriefing guided by the facilitator, who analysed team performance of $\mathrm{D}-\mathrm{CPR}$ in relation to the learning objectives.

\section{Assessment of team performance and development of the D-CPR checklist}

We developed a 23-item check list (D-CPR checklist) with a total score range from 0 to 19 (items 1-19) and the actual number of seconds was used for three items (item 20, 21 and 24) to assess D-CPR team performance because no D-CPR checklist in Norwegian existed (Additional file 1). The D-CPR checklist was based on the Cardiff test protocol [23] and the checklist developed by Kromann et al. [22].

The Cardiff Test for basic life support (BLS) and the use of an automated external defibrillator (AED) from 2000 has been developed from previous editions and uses criterion-referenced assessments to evaluate CPR and AED performance from analysis of video recordings and data drawn from a computer attached to a training mannequin. The European Resuscitation Guidelines for CPR and AED were revised in 2005, and the D-CPR checklist in this study was revised accordingly [21]. The checklist 
developed by Kromann et al. [22] was based on the Advanced Life Support Cardiac Arrest Scenario Test checklist from 2005 [24]. For this study it was adjusted to assessment of basic life support and use of AED.

The researchers collaboratively designed the D-CPR checklist to match the curriculum of the course and expected team performance. For items 1 to 19, "yes" was coded as 1 and "no" as 0 (19 possible points). For items 20-24, time from discovery of unconsciousness until chest compressions started, time from discovery of unconsciousness until shock was delivered and hands-off time in relation to first shock the actual number of seconds was used. Firstly, two researchers independently assessed the performance of Group A and B in four of the cardiac arrest simulations. This served to refine the checklist, adjust items and calibrate judgments. Secondly, the two researchers independently assessed team performance for each item of the checklist in the remaining 24 scenarios. Thereafter, three errors of time registration were corrected, as these were caused by miscalculations. Seven differences in relation to timing of unconsciousness (item 20-21) were kept unchanged as these were caused by the difference between the two researchers in defining the exact point of time for discovering unconsciousness. Item 24 was calculated as the sum of items 22 and 23, and a summary of points for all teams according to each of the 19 items in the DCPR-checklist was made. Further, the points given to each team by the two assessors were summarized separately and the mean values of the two sums were calculated.

\section{Statistics}

Paired samples $t$-test was used for analyses of variables with normal distribution, i.e. item 1 to 19 , time from discovery of unconsciousness until chest compressions started (item 20) and time from discovery of unconsciousness until shock was delivered (item 21). The Wilcoxon signed rank test was used on item 24 (Hands-off time in relation to first shock) due to abnormal distribution. For parametric tests, the mean value with standard deviation (SD) was calculated. For non-parametric tests, the median values with interquartile range were calculated. All tests were two-sided and statistical significance was considered as $P<0.05$. All analyses were performed with SPSS version 18 (Chicago, IL). Rater agreement, defined as the number of agreed assessments $(x+y)$ divided by the number of agreed assessments + the number of disagreed assessments (z) [25], was calculated using the fraction: $\%=\frac{x+y}{(x+y)+z}$ (Additional file 2$)$. However, this calculation has at least two weaknesses: it takes no account of where in the checklist the agreement was, and we would expect some agreement between the two raters by chance, even if they were guessing. We therefore calculated inter-rater reliability of the video assessment with kappa and linear weighting using VassarStats $^{\mathrm{a}}$ (Additional file 2). It has been proposed that a kappa score of 0.81-1.00 indicates very good agreement, 0.41-0.80 moderate to good agreement, 0.21-0.40 fair agreement and below 0.20 poor agreement [26].

\section{Reliability of the D-CPR checklist}

Rater agreement for assessment of the D-CPR checklist was $0.88\left(88 \%=\frac{318+149}{(318+149)+65}\right)$ indicating a reliable checklist. Items regarding application of skills and medical devices received highest agreement between the two assessors (e.g. item 1. Checked response verbally, item 3. Opened the airways, item 5. Verbally stated cardiac arrest, and item 9. Counted aloud), whereas items regarding subjective data of D-CPR (e.g. item 2. Checked response by shaking, item 4. Checked breathing for a max. $10 \mathrm{~s}$., and item 18. Said all away from the patient) received lowest agreement (Additional file 2). The inter-rater reliability is shown in Additional file 2. There was very good or good strength agreement for nine items. However, there was fair strength of agreement on checking response by shaking, checking breathing and standing on their toes (Additional file 2). Differences between rater 1 and rater 2 in time variables (item 20, 21 and 24) demonstrated that one rater (rater 2) consistently assessed time intervals longer than the other (Additional file 3).

\section{Results}

\section{Team performance of D-CPR}

The nursing student teams achieved on average $59 \%$ of the D-CPR-checklist points $\left(x=\frac{\text { numbers of assessment with correct performance }(\mathrm{n}=318)}{\text { number of teams }(n=28) \times \text { numbers of items }(\mathrm{n}=19)}=59 \%=\frac{318}{532}\right)$ (Additional file 2). Twenty-five (89\%) of 28 teams performed checking response verbally, while only 12 (43\%) teams checked response by shaking as prescribed by the guidelines (Figure 2). Opened the airways was the most poorly performed part of the D-CPR. Only seven teams $(25 \%)$ checked breathing for a maximum $10 \mathrm{~s}$. The most correctly performed part of the D-CPR was the use of a 30:2 ratio in compressions and ventilation (Figure 2). All but one (96\%) team applied the backboard while they performed chest compressions. Twenty-five (89\%) teams attached pads correctly. All nursing student teams started chest compressions $<2$ min. from discovery of unconsciousness. Twenty (72\%) teams took $<3$ min. from discovery of unconsciousness until shock was delivered and none of the 


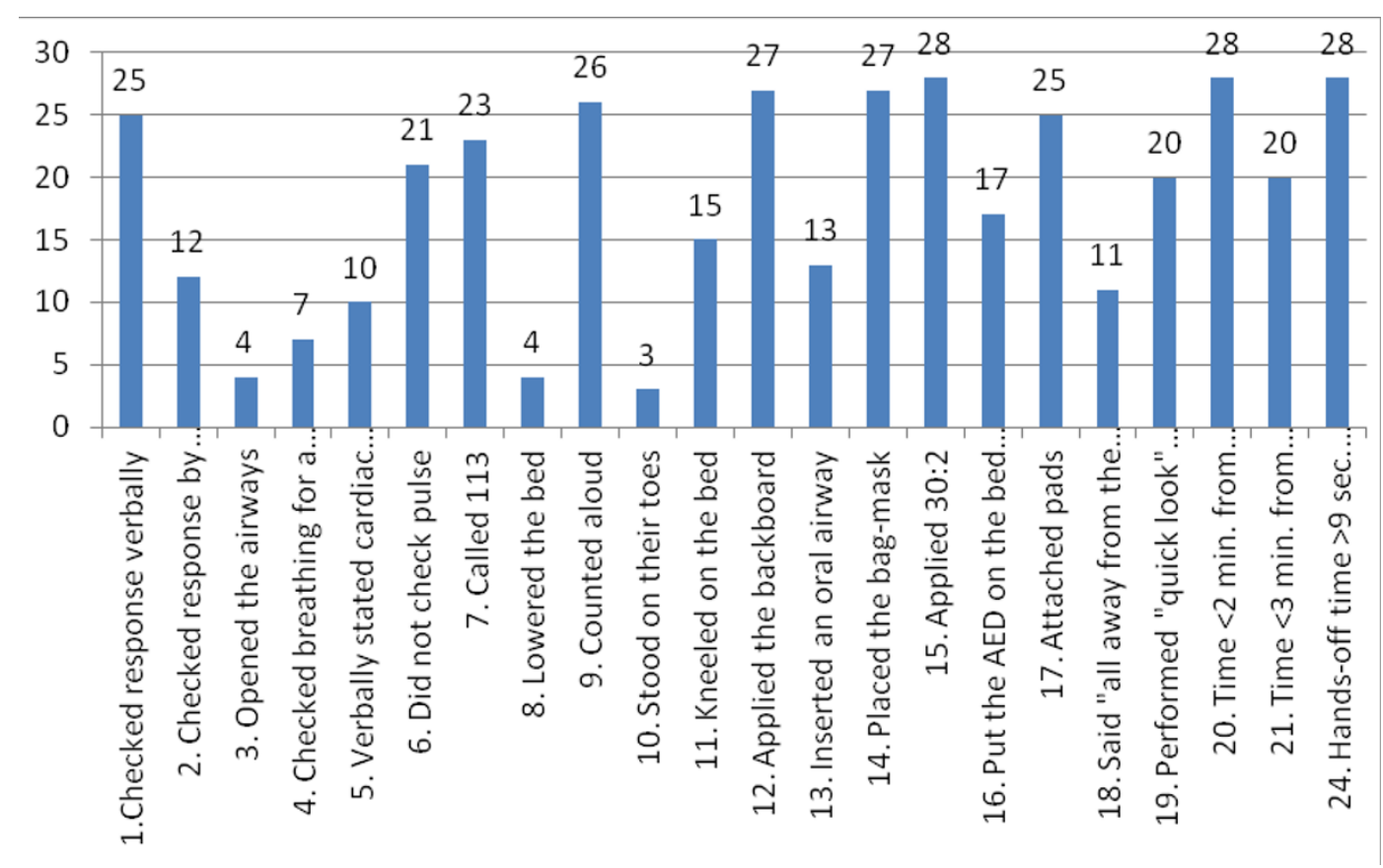

Figure 2 The number of nursing student teams $(\mathbf{n}=\mathbf{2 8})$ that followed the D-CPR checklist. Teams for which there is disagreement in the assessed items are not included.

teams had $<9$ s. hands-off time in relation to first shock (Figure 2).

\section{Differences between group A and B in D-CPR performance}

When comparing Group A and Group B there were no significant differences in performance of D-CPR either in total points (item 1-19) or time variables (item 20, 21 and 24) (Table 1). There was a small increase in total points of D-CPR performance for Group B, but the changes were not significant. When it comes to time from discovery of unconsciousness until chest compressions started Group B took on average $2 \mathrm{~s}$ more than Group A (item 20). Group $\mathrm{B}$ also took on average $4 \mathrm{~s}$ more than Group A from discovery of unconsciousness until shock was delivered (item 21). Hands-off time in relation to first shock was more or less the same for both groups (item 24).

\section{Discussion}

The results of our study indicate that most of the nursing student teams did not perform the D-CPR-checklist accurately. We could also demonstrate that observing one simulated cardiac arrest scenario and participating in one post simulation debriefing did not show a significant improvement in performance of D-CPR. These findings can at first sight appear as somewhat surprising since feedback in the debriefing has been identified as the most important feature of simulation-based education and a necessary condition for changing performance $[27,28]$. In the debriefings, the active students were encouraged to reflect on and analyse their own performance leading to meaningful learning [29], whilst the observing nursing student teams were asked to reflect on the performance of the active teams and to keep that in mind for their subsequent simulation. Consequently, it might have been too demanding for these teams to both apply the D-CPR algorithm and simultaneously apply the newly acquired insight from their observations in the subsequent scenario [20]. A second explanation for the results of our study is that it takes more than one simulation and repetitive practice with feedback to perform D-CPR with accuracy $[5,14,30,31]$. In the present study the nursing

Table 1 D-CPR Checklist points and measured time intervals for Group A and Group B assessed via video-recordings

\begin{tabular}{llll}
\hline Items & Group A $(\mathbf{n}=\mathbf{1 4})$ & Group B (n = 14) & P \\
\hline D-CPR performance (item 1-19)* & $12(11-14)$ & $13(11-15)$ & .566 \\
\hline Time (sec.) from discovery of unconsciousness until chest compressions started (item 20) & $36 \pm 16$ & $38 \pm 16$ & .744 \\
\hline Time (sec.) from discovery of unconsciousness until shock was delivered (item 21) & $145 \pm 61$ & $149 \pm 44$ \\
\hline Hands-off time (sec.) in relation to first shock (item 24)* & $33(28-40)$ & $33(28-44)$ & .608 \\
\hline
\end{tabular}

Mean values \pm standard deviation (* median values with interquartile range) 
student that were active in the second simulation had neither practiced themselves, nor got feedback on their performance before acting in the scenario.

In terms of D-CPR team performance, the findings are discouraging, in that procedures such as opening the airways and examination of breathing were not satisfactory. However, this does not mean that the nursing student teams failed to develop any of the D-CPR skills. The findings clearly demonstrated that the student teams achieved almost two-thirds (59\%) of the D-CPR-checklist points by participating in a simulated cardiac arrest scenario. These findings are in line with the results of a study that compared a traditional, small-group D-CPR course with an Internet-based D-CPR course teaching basic life support [32]. Mäkinen et al. found that nurses receiving the traditional, small-group D-CPR course performed better than those receiving the Internet-based DCPR course [32]. The importance of leadership in team performance has been demonstrated in previous research $[33,34]$, but assessing leadership was beyond the scope and intent of this article.

The mean time from discovery of unconsciousness until chest compressions started was $36.3 \mathrm{~s}$ in Group A and $38 \mathrm{~s}$ in Group B. All teams took $<2 \mathrm{~min}$. until chest compressions were initiated. Previous research has shown that the interval between discovery of unconsciousness until chest compressions start affects survival in cardiac arrest [35]. Holmberg et al. found that there was significantly increased survival at one month for patients who received CPR $\leq 2$ min after collapse compared to patients who received $\mathrm{CPR}>2 \mathrm{~min}$. after collapse [35]. Our results indicate that all nursing student teams understood the importance of acting rapidly and starting chest compressions early to increase survival after cardiac arrest. If the teams had further trained in recognizing a cardiac arrest by stating unconsciousness and confirming abnormal breathing, the time to first chest compression could possibly have been further reduced.

Time from discovery of unconsciousness until shock is delivered influences survival in in-hospital cardiac arrest [36]. Herlitz et al. demonstrated that the overall survival rates were $72 \%$ for patients defibrillated within $3 \mathrm{~min}$. after collapse on non-monitored wards [36]. In our study we found that, on average, all teams delivered first shock within the first three minutes, but the variance within the teams was large. This means that 8 teams took $>3 \mathrm{~min}$. from discovery of unconsciousness until shock was delivered. These findings may be explained by confusion as to whether to deliver immediate defibrillation in case of witnessed cardiac arrest was appropriate or whether to execute $3 \mathrm{~min}$. of CPR before defibrillation in case of non-witnessed cardiac arrest (Norwegian Resuscitation Council). This observation calls for a clear explanation of the correct algorithm to follow and more attention to early defibrillation in simulation-based D-CPR courses in nursing education; it should be specifically highlighted in the debriefing.

The results demonstrated that all teams spent too long hands-off time in relation to first shock. Hands-off time in relation to first shock is associated with decrease in survival [37]. A recent study aiming to define the optimal pre- and post-defibrillation compression pauses for out-of-hospital cardiac arrest revealed that hands-off time $>9 \mathrm{~s}$. in relation to first shock decreased the return of spontaneous circulation [38]. The long time intervals concerning hands-off time in relation to first shock have educational implications.

In summary, this study has demonstrated that observing one simulation performed by another team and participating in its debriefing does not improve nursing student performance in a subsequent simulated cardiac arrest scenario. Further, this study has demonstrated that the five-hour program in D-CPR is insufficient for learning to perform D-CPR correctly. There is reason to believe that the program should include repetitive practice, feedback and testing of D-CPR performance, as previously demonstrated by Oermann et al. and Sutton et al. $[30,31]$.

The major limitations of this study were its small sample size as well as its limitation of having been carried out in one nursing education institution, in one geographical location in Norway. Ideally, the design of the educational study should include a pre-test. However, in this study, a pre-test to examine if different conditions would change the team performance of D-CPR could possibly have influenced the performance of teams in Group A. To strengthen reliability, mannequin-based data of CPR performance should be used in addition to observational data [39]. The video observations in this study demonstrate that the raters assessed some aspects of D-CPR performance in different ways, indicated by some large inter-observer differences. The use of medical devices (e.g. bag-mask, oro-pharyngeal airway and backboard) is easy to assess, whereas aspects of D-CPR such as "checked response by shaking" and "checked breathing for a max. 10 s." depends on the individual investigators' judgment and interpretation. The difference in two time variables (item 20 and 21) between the two raters probably means that defining the exact point of time for discovering unconsciousness is different. These results are contrary to the findings in a study that assessed Advanced Life Support competence and found good reliability of the scores [40]. One reasonable explanation of the variations in inter-rater agreement in this study is that the two raters did not make a consensus scoring after the first individual assessment as in Ringsted et al. [40]. 


\section{Conclusion}

This study revealed that observing training of other teams and participating in the debriefing did not itself improve performance of D-CPR in nursing student teams. The findings call for more time for repetitive practice and reflection and highlight that the most important aspects of D-CPR, like early defibrillation and hands-off time in relation to shock, must be emphasised during team training of nursing students.

\section{Endnote}

ahttp://faculty.vassar.edu/lowry/VassarStats.html accessed in January 2012.

\section{Additional material}

Additional file 1: The D-CPR checklist.

Additional file 2: The number of nursing student teams $(n=28)$ that followed the D-CPR checklist, number of items with agreement and disagreement between the two raters, mean $\left({ }^{*}\right.$ median) values of time variables and kappa with linear weighting.

Additional file 3: Differences between rater 1 and rater 2 in time variables, item 20 Time (sec.) from discovery of unconsciousness until chest compressions started, 21 Time (sec.) from discovery of unconsciousness until shock was delivered and 24 Hands-off time (sec.) in relation to first shock.

\section{Author details}

'Department of Health Studies, Faculty of Social Sciences, University of Stavanger, Stavanger 4036, Norway. ${ }^{2}$ Department of Anaesthesiology and Intensive Care, Stavanger University Hospital, PO Box 8100, Stavanger 4068, Norway. ${ }^{3}$ Department of Education, Communication and Learning, University of Gothenburg, Läroverksgatan 15, PO Box 300, Gothenburg SE 405 30, Sweden. ${ }^{4}$ Institute of Health and Care Sciences, Sahlgrenska Academy at University of Gothenburg, PO Box 100, Gothenburg S-405 30, Sweden.

\section{Authors' contributions}

SEH participated in the design and planning of the study and the development of the D-CPR checklist; collected the data, assessed the video recordings, performed the descriptive statistics, wrote the manuscript draft, and coordinated the subsequent versions of the manuscript. CAB participated in the development of the D-CPR checklist, assessed the video recordings, performed the statistical analysis, and made important additions in drafting the manuscript. HR and FF participated in the design and planning of the study, revised the study manuscript and made important additions. ES participated in the design and planning of the study and was involved in drafting and revising the manuscript. All authors have reviewed the submitted version. All authors read and approved the final manuscript.

\section{Competing interests}

SEH is employed part-time (25\%) as Training Coordinator of University Programs at Stavanger Acute Medicine Foundation for Education and Research (SAFER). CAB is employed part-time (20\%) as a facilitator at SAFER. ES is medical director at SAFER. SEH has received financial support from the Laerdal Foundation for Acute Medicine but otherwise the authors declare they have no competing interests and no financial disclosures.

Received: 19 November 2011 Accepted: 2 April 2012

Published: 2 April 2012
References

1. Bruce SA, Scherer YK, Curran CC, Urschel DM, Erdley S, Ball LS: A COLLABORATIVE EXERCISE: Between Graduate and Undergraduate Nursing Students Using a COMPUTER-ASSISTED SIMULATOR in a Mock Cardiac Arrest. Nurs Educ Perspect 2009, 30(1):22-27.

2. Davies N, Gould D: Updating cardiopulmonary resuscitation skills: a study to examine the efficacy of self-instruction on nurses' competence. J Clin Nurs 2000, 9(3):400-410.

3. Hamilton R: Nurses' knowledge and skill retention following cardiopulmonary resuscitation training: a review of the literature. J Adv Nurs 2005, 51(3):288-297.

4. Preusch MR, Bea F, Roggenbach J, Katus HA, Junger J, Nikendei C: Resuscitation Guidelines 2005: does experienced nursing staff need training and how effective is it? Am J Emerg Med 2010, 28(4):477-484.

5. Madden C: Undergraduate nursing students' acquisition and retention of CPR knowledge and skills. Nurse Educ Today 2006, 26(3):218-227.

6. Badger T, Rawstorne D: An evaluative study of pre-registration nursing students' skills in basic life support. Nurse Educ Today 1998, 18(3):231-236.

7. Hammond F, Saba M, Simes T, Cross R: Advanced Life Support: retention of registered nurses' knowledge 18 months after initial training. Aust Crit Care 2000, 13(3):99-104.

8. Liaw SY, Rethans J-J, Scherpbier A, Piyanee K-Y: Rescuing A Patient In Deteriorating Situations (RAPIDS): a simulation-based educational program on recognizing, responding and reporting of physiological signs of deterioration. Resuscitation 2011, 82(9):1224-1230.

9. Lupien AE, George-Gay B: High-fidelity Patient Simulation. In Fuszard's innovative teaching strategies in nursing. Edited by: Lowenstein AJ, Bradshaw MJ. Gaithersburg: Aspen Publishers; 2010:378 s.

10. Flisher D: Improving nurses' resuscitation skills. Nurs Stand 1992, 6(50):32-35.

11. Rivera TM, Gabriel S: How effectively do you function in a cardiac arrest? A creative program approach to code skills. J Contin Educ Nurs 1995, 26(5):226-229.

12. Granneman SBSNRN, Conn VSPRN: An Evaluation of the Effectiveness of Competency-Based Code Blue Education. Journal of Nursing Staff Development November/December 1996, 12(6):283-288.

13. Wadas TM: Role rehearsal: a mock code program. Nurs Manage 1998, 29(10):48E.

14. Linnard-Palmer $L$ : The effect of a skills algorithm on nursing students' response rate, skill accuracy, and reported attention management during simulated cardiopulmonary arrests. San Francisco: University of San Francisco; 1996.

15. Scherer YK, Bruce SA, Runkawatt V: A comparison of clinical simulation and case study presentation on nurse practitioner students' knowledge and confidence in managing a cardiac event. Int I Nurs Educ Scholarsh 2007, 4(1):1-14.

16. Childs JC, Sepples S: Clinical teaching by simulation: lessons learned from a complex patient care scenario. Nurs Educ Perspect 2006, 27(3):154-158.

17. Kardong-Edgren SE, Starkweather AR, Ward LD: The integration of simulation into a clinical foundations of nursing course: student and faculty perspectives. Int J Nurs Educ Scholarsh 2008, 5(1):1-16.

18. Pascual JL, Holena DN, Vella MA, Palmieri J, Sicoutris C, Selvan B, Fox AD, Sarani B, Sims C, Williams NN, et al: Short simulation training improves objective skills in established advanced practitioners managing emergencies on the ward and surgical intensive care unit. J Trauma 2011, 71(2):330-338.

19. Husebø SE, Friberg F, Søreide E, Rystedt H: Instructional Problems in Briefings: How to Prepare Nursing Students for Simulation-Based Cardiopulmonary Resuscitation Training. Clinical Simulation in Nursing , doi:101016/jecns201012002 2011(0).

20. Husebø SE, Rystedt H, Friberg F: Educating for teamwork - nursing students' coordination in simulated cardiac arrest situations. J Adv Nurs 2011, 67(10):2239-2255.

21. Handley AJ, Koster R, Monsieurs K, Perkins GD, Davies S, Bossaert L: European Resuscitation Council Guidelines for Resuscitation 2005: Section 2. Adult basic life support and use of automated external defibrillators. Resuscitation 2005, 67(Supplement 1(0)):S7-S23.

22. Kromann $C B$, Jensen $M L$, Ringsted C: The effect of testing on skills learning. Medical Education 2009, 43(1):21-27. 
23. Whitfield RH, Newcombe RG, Woollard M: Reliability of the Cardiff Test of basic life support and automated external defibrillation version 3.1. Resuscitation 2003, 59(3):291-314

24. Nolan JP, Deakin CD, Soar J, Böttiger BW, Smith G: European Resuscitation Council Guidelines for Resuscitation 2005: Section 4. Adult advanced life support. Resuscitation 2005, 67(Supplement 1):S39-S86.

25. Dyrholm Siemensen IM: Et eksplorativet studie av faktorer der påvirker sikkerheten af patient-overgange (An explorative study of factors influencing safety in patient handovers). Lyngby: Danmarks Tekniske Universitet; 2011.

26. Fleiss JL, Levin B, Paik MC: The Measurement of Interrater Agreement. In Statistical Methods for Rates and Proportions. Edited by: Fleiss JL, Levin B, Paik MC. Hoboken, NJ: John Wiley 2004:598-626.

27. Issenberg SB, McGaghie WC, Petrusa ER, Gordon DL, Scalese RJ: Features and uses of high-fidelity medical simulations that lead to effective learning: a BEME systematic review. Medical Teacher 2005, 27(1):10-28.

28. Seropian MA, Brown K, Gavilanes JS, Driggers B: Simulation: not just a manikin. J Nurs Educ 2004, 43(4):164-169.

29. Dreifuerst $K T$ : The essentials of debriefing in simulation learning: a concept analysis. Nurs Educ Perspect 2009, 30(2):109-114.

30. Oermann MH, Kardong-Edgren SE, Odom-Maryon T: Effects of monthly practice on nursing students' CPR psychomotor skill performance. Resuscitation 2011, 82(4):447-453.

31. Sutton RM, Niles D, Meaney PA, Aplenc R, French B, Abella BS, Lengetti EL, Berg RA, Helfaer MA, Nadkarni V: Low-Dose, High-Frequency CPR Training Improves Skill Retention of In-Hospital Pediatric Providers. Pediatrics 2011, 128(1):e145-e151.

32. Mäkinen $M$, Castrèn $M$, Tolska T, Nurmi J, Niemi-Murola L: Teaching basic life support to nurses. European Journal Of Anaesthesiology 2006, 23(4):327-331.

33. Siassakos D, Fox R, Crofts JF, Hunt LP, Winter C, Draycott TJ: The management of a simulated emergency: Better teamwork, better performance. Resuscitation 2011, 82(2):203-206.

34. Hunziker S, Bühlmann C, Tschan F, Balestra G, Legeret C, Schumacher C, Semmer NK, Hunziker P, Marsch S: Brief leadership instructions improve cardiopulmonary resuscitation in a high-fidelity simulation: A randomized controlled trial. Crit Care Med 2010, 38(4):1086-1091.

35. Holmberg M, Holmberg $\mathrm{S}$, Herlitz for the Swedish Cardiac Arrest Registry J: Factors modifying the effect of bystander cardiopulmonary resuscitation on survival in out-of-hospital cardiac arrest patients in Sweden. Eur Heart J 2001, 22(6):511-519.

36. Herlitz J, Aune $S$, Bång A, Fredriksson M, Thorén A-B, Ekström L, Holmberg S: Very high survival among patients defibrillated at an early stage after in-hospital ventricular fibrillation on wards with and without monitoring facilities. Resuscitation 2005, 66(2):159-166.

37. Cheskes S, Schmicker RH, Christenson J, Salcido DD, Rea T, Powell J, Edelson DP, Sell R, May S, Menegazzi JJ, et al: Perishock Pause/Clinical Perspective. Circulation 2011, 124(1):58-66.

38. Sell RE, Sarno R, Lawrence B, Castillo EM, Fisher R, Brainard C, Dunford JV, Davis DP: Minimizing pre- and post-defibrillation pauses increases the likelihood of return of spontaneous circulation (ROSC). Resuscitation 2010, 81(7):822-825.

39. Lynch B, Einspruch EL, Nichol G, Aufderheide TP: Assessment of BLS skills: Optimizing use of instructor and manikin measures. Resuscitation 2008, 76(2):233-243.

40. Ringsted C, Lippert F, Hesselfeldt R, Rasmussen MB, Mogensen SS, Frost T, Jensen ML, Jensen MK, Van der Vleuten C: Assessment of Advanced Life Support competence when combining different test methods-Reliability and validity. Resuscitation 2007, 75(1):153-160.

doi:10.1186/1757-7241-20-23

Cite this article as: Eikeland Husebø et al: A comparative study of defibrillation and cardiopulmonary resuscitation performance during simulated cardiac arrest in nursing student teams. Scandinavian Journal of Trauma, Resuscitation and Emergency Medicine 2012 20:23.

\section{Submit your next manuscript to BioMed Central and take full advantage of:}

- Convenient online submission

- Thorough peer review

- No space constraints or color figure charges

- Immediate publication on acceptance

- Inclusion in PubMed, CAS, Scopus and Google Scholar

- Research which is freely available for redistribution 